\title{
LA PROTECCIÓN DEL AMBIENTE EN LA NUEVA LEY DE CONTRATOS: DEL ESTADO MERAMENTE "COMPRADOR» AL ESTADO «ORDENADOR»
}

\author{
ÍNIGO SANZ RUBIALES \\ Universidad de Valladolid \\ isanz@der.uva.es
}

Cómo citar/Citation

Sanz Rubiales, Í. (2018).

La protección del ambiente en la nueva ley de contratos: del Estado meramente «comprador» al Estado «ordenador».

Revista de Administración Pública, 205, 49-80.

doi: https://doi.org/10.18042/cepc/rap.205.02

\section{Resumen}

La nueva ley de contratos públicos potencia la utilización de cláusulas ambientales en la contratación pública. Debe destacarse, en este sentido, la introducción de los costes del ciclo de vida como criterio económico-ambiental de adjudicación de los contratos, así como el control de la legalidad ambiental de la actividad del contratista por el órgano de contratación. Se puede decir que, en materia de contratos públicos, el Estado meramente «comprador» se está transformando en un Estado «ordenador».

\section{Palabras clave}

Contratación pública; cláusulas ambientales; costes del ciclo de vida.

\section{Abstract}

The new Public Procurement Law promotes the use of environmental clauses in public procurement. In this sense, the introduction of life-cycle costs as an economicenvironmental criterion for the award of contracts should be highlighted, as well as 
the control of the environmental legality of the contractor's activity by the contracting authority. It may be said that, in matters of public procurement, the merely "buyer" State is being transformed into a "regulator" State.

\section{Keywords}

Public procurement; environmental clauses; life-cycle costs. 


\section{SUMARIO}

I. INTRODUCCIÓN. II. LA CONTRATACIÓN PÚBLICA VERDE COMO FORMA DE ACTIVIDAD ADMINISTRATIVA DE ORDENACIÓN DE LA ACTUACIÓN PRIVADA: 1. De la mera provisión de bienes y servicios a la finalidad estratégica ambiental: el principio de integración. 2. Constituye una medida de fomento: sus dos efectos. 3. Su utilización como técnica instrumental de policía en la nueva Ley 9/2017. III. PRINCIPIOS QUE RIGEN LA INTRODUCCIÓN DE CRITERIOS AMBIENTALES EN LA NUEVA LEY DE CONTRATOS: 1. La «obligación» de incluir requisitos ambientales y sus posibilidades de inserción. 2. El respeto de los demás principios comunitarios de la contratación. 3. En especial, la necesaria relación con el objeto: 3. 1. Justificación y alcance. 3.2. Las cláusulas «estratégicas» no deben desnaturalizar la «oferta económicamente más ventajosa». 3.3. A diferencia de las cláusulas «sociales», las ambientales pueden tener un valor elevado en la adjudicación. 3.4. ¿Caben cláusulas ambientales «subjetivas»? 4. Promoción del uso de etiquetas y certificados de ecoauditorías y sus límites como prueba del cumplimiento de requisitos ambientales. 5. La necesaria coherencia con las demás finalidades estratégicas de la contratación pública. IV. LAS NOVEDADES DE LA LEY 9/2017 EN LAS DISTINTAS MODALIDADES DE CLÁUSULAS AMBIENTALES: 1. La acertada «ambientalización» de los criterios económicos de adjudicación de los contratos: 1.1. El nuevo criterio de los costes del «ciclo de vida» como demostración de que los costes ambientales son también económicos. 1.2. La obligación de rechazar bajas temerarias por incumplimiento de la legalidad ambiental. 2. El nuevo control de la legalidad ambiental en la ejecución del contrato: 2.1. ¿̇un nuevo privilegio? 2.2. La incidencia del control de legalidad sobre el régimen de responsabilidad por daños a terceros. 2.3. Crítica. V. CONCLUSIONES.

\section{INTRODUCCIÓN}

Los objetivos del régimen de la contratación pública han sido, y son, conseguir una gestión eficiente de los fondos públicos y garantizar la libre concurrencia en el acceso a las licitaciones públicas ${ }^{1}$. Pero «comprar es siem-

1 J. J. Pernas García (2012), Contratación pública verde, Madrid: La Ley (pág. 214). 
pre un acto moral, y no solo económico ${ }^{2}$. Y si lo es para los particulares, con mayor razón para los poderes públicos, que manejan presupuestos inmensos y que tienen una enorme capacidad de influir y de transformar la sociedad, canalizando fondos públicos hacia objetivos estratégicos ${ }^{3}$. En este sentido, la reciente Ley 9/2017, de 8 de noviembre, de Contratos del Sector Público, por la que se transponen al ordenamiento jurídico español las Directivas del Parlamento Europeo y del Consejo 2014/23/UE y 2014/24/UE, de 26 de febrero de 2014, refuerza la utilización instrumental de la contratación pública para alcanzar objetivos ambientales de producción y consumo sostenibles, y lo hace a través de la incorporación y, en su caso, mejora de diversas técnicas. En este trabajo se analizan los principales problemas jurídicos que se generan como consecuencia de la incidencia de las «nuevas» técnicas de contratación «verde» en los «viejos» principios de la contratación pública, en el marco de la constatación de que los contratos públicos, tal y como los configura la nueva ley, se han convertido en un instrumento de estímulo (fomento) e incluso restrictivo (policía) de ordenación de la actividad de los administrados en la protección del ambiente.

\section{LA CONTRATACIÓN PÚBLICA VERDE ${ }^{4}$ COMO FORMA DE ACTIVIDAD ADMINISTRATIVA DE ORDENACIÓN DE LA ACTUACIÓN PRIVADA}

\section{DE LA MERA PROVISIÓN DE BIENES Y SERVICIOS A LA FINALIDAD ESTRATÉGICA AMBIENTAL: EL PRINCIPIO DE INTEGRACIÓN}

¿Los contratos públicos constituyen una técnica de protección ambiental? Per se no lo son: constituyen, simplemente, un medio de que la Administración

2 Cfr. Papa Francisco (2015), Laudato si (n. 206).

3 Cfr. J. M. Gimeno Feliú (2013), «Compra pública estratégica», en J. J. Pernas García (coord.), Contratación Pública Estratégica (págs. 45-79), Cizur Menor: Thomson Reuters Aranzadi. Véase, igualmente, J. Rodríguez-Arana Muñoz (2013), «La contratación del sector público como política pública», en J. J. Pernas García (coord.), Contratación Pública Estratégica (págs. 31-45), Cizur Menor: Thomson Reuters Aranzadi.

4 La contratación pública verde es definida por la Comisión Europea como «un proceso por el cual las autoridades públicas tratan de adquirir mercancías, servicios y obras con un impacto medioambiental reducido durante su ciclo de vida, en comparación con el de otras mercancías, servicios y obras con la misma función primaria que se adquirirían en su lugar» (Comunicación de la Comisión Europea «Contratación pública para un medio ambiente mejor», de 2 de julio de 2008, COM(2008) 400, pág. 4). 
se procure bienes y servicios. Sin embargo, la utilización instrumental de esta forma de provisión para mejorar el ambiente se ha venido potenciando en el marco del derecho comunitario, fundamentalmente sobre la base de las directivas de contratos ya derogadas de 2004, la jurisprudencia comunitaria, la Comunicación de la Comisión sobre Contratación pública para un medio ambiente mejor ${ }^{5}$, la Estrategia Europa $2020^{6}$ y, finalmente, las vigentes directivas «contratos» de 20147 , cuya transposición opera la ley recién aprobada. No es casual que haya sido el derecho comunitario el que ha venido a estimular la contratación pública como vía de protección ambiental: este imaginativo aprovechamiento de la potencialidad de la contratación pública responde al principio de integración del medio ambiente en las demás políticas europeas, recogido en el art. 35 de la Carta de Derechos Fundamentales de la UE y en el art. 11 TFUE: «Las exigencias de la protección del medio ambiente deberán integrarse en la definición y en la realización de las políticas y acciones de la Unión, en particular con objeto de fomentar un desarrollo sostenible».

Este principio vino a confirmar la viabilidad de las cláusulas ambientales que, sin embargo, se habían venido utilizando con naturalidad en los contratos públicos en España, tanto a título de criterios de adjudicación como a título de condiciones de ejecución o de cláusulas técnicas. Así, los criterios de adjudicación "ambientales» han tenido cabida tradicionalmente en los concursos $^{8}$; pero también la han tenido condiciones de ejecución y prescripciones

5 R. Caranta (2010), «Sustainable Public Procurement in the EU», en R. Caranta y M. Trybus (eds.), The Law of Green and Social Procurement in Europe (págs. 15-52), Copenhagen: DJØF Publishing. Sobre la aplicabilidad del principio de integración ambiental en la política de contratos públicos, antes incluso de la reforma de las directivas contratos de 2004, véase la STJCE de 17 de diciembre de 2002 en el as. 513/99, Concordia Bus Finland. Cfr. B. Lozano Cutanda y J. C. Allí Turrillas (2016), Administración y legislación ambiental, 9a ed., Madrid: Dykinson (pág. 191); J. M. Gimeno Feliú (2015), «La “codificación” de la contratación pública mediante el derecho pretoriano derivado de la jurisprudencia del TJUE», Revista Española de Derecho Administrativo, 172 (págs. 81-122).

6 Comunicación de la Comisión «Europa 2020. Una estrategia para un crecimiento inteligente, sostenible e integrador», $\mathrm{COM(2010)} 2020$ final, Bruselas, 3.3.2010.

7 Cfr. S. Rodríguez-Campos (2016), Las nuevas directivas de contratos públicos y su transposición, Madrid: Marcial Pons (págs. 38 y ss., 244 y ss., etc.).

$8 \quad$ P. ej., mediante Orden Ministerial de 14 de octubre de 1997 (BOE, 259, de 29 de octubre de 1997) se fijaron los criterios de modificación de los pliegos de cláusulas administrativas particulares que debían regir la contratación en el Ministerio de Medio Ambiente - y en los organismos públicos de él dependientes — para incluir la valoración ambiental como exigencia objetiva de resolución de los concursos que se convocaran. Por eso, en ese aspecto, la previsión de la Ley 30/2007, de Contratos, en 
técnicas vinculadas con el medio ambiente: la legislación de evaluación de impacto ambiental de proyectos impone, desde 1986, el condicionamiento ambiental en los proyectos de obras públicas sometidos a dicha normativa, condicionamiento que, lógicamente, se traslada al clausulado técnico del contrato de obras correspondiente.

\section{CONSTITUYE UNA MEDIDA DE FOMENTO: SUS DOS EFECTOS}

Cuando los contratos públicos establecen condiciones o requisitos ambientales en los pliegos, no imponen unilateralmente nuevas obligaciones de protección ambiental, pero estimulan la producción «verde» al condicionar la posibilidad de contratar con los poderes públicos al cumplimiento de determinados requisitos (que incluyen el cumplimiento de la normativa ambiental pero que van más allá de lo estrictamente obligatorio); desde esta perspectiva, la política de contratación pública puede configurarse como una técnica de "fomento» o estímulo de la actuación privada «ajustada» al interés público?. En efecto, con la contratación verde la Administración estimula a las empresas para que, libremente, cambien sus técnicas de producción, a cambio de la ventaja de participar y, en su caso, ser adjudicatarias de un contrato público. La Ley de Contratos habilita a la Administración para otorgar «beneficios» (vía adjudicación del contrato) a quienes cumplan la prestación pactada de la forma más respetuosa con el medio ambiente.

Son dos los efectos ambientales que el estímulo de la contratación «verde» genera, más allá del mero cumplimiento de la legalidad ambiental: por una parte, el efecto directo, esto es, el hecho real de que un porcentaje importante - en algunos casos, muy elevado- de los productos objeto de mercado (en concreto, los provistos por los contratistas a la Administración) se ajustarán a criterios de impacto ambiental reducido, de tal manera que la actividad de las administraciones públicas «puede contribuir de manera importante a la consecución de los objetivos de sostenibilidad locales, regionales, nacionales e internacionales», porque las compras o encargos públicos constituyen una parte muy importante de la totalidad de adquisiciones de un país. Pero, por otra, tiene también un efecto «reflejo», fruto de la «llamada» de la Administración

desarrollo de la Directiva 2004/18, de la posible introducción de cláusulas ambientales, afectó solo parcialmente a la práctica contractual: cfr. J. F. Mestre Delgado (2009), "Oferta económicamente más ventajosa», en J. Bermejo Vera (dir.), Diccionario de contratación pública, Madrid: Iustel, págs. 427-435 (pág. 431).

9 Cfr., igualmente, A. Betancor Rodríguez (2014), Derecho Ambiental, Madrid: La Ley (pág. 1459). 
al sector privado ${ }^{10}$; este efecto incentivador del desarrollo de procesos, productos y servicios «ecológicos» es consecuencia de las grandes ventajas que tiene, en general, la adjudicación de contratos públicos para las empresas privadas. Esta posibilidad próxima de ser adjudicatario de contratos públicos disuade también de la posible deslocalización de la empresa como consecuencia de las cargas ambientales, porque genera expectativas de demanda de la producción ambientalmente responsable ${ }^{11}$.

De esta forma, a través de la contratación, la Administración no solo adquiere, sino que ordena mediante incentivos la actividad de los sujetos pri$\operatorname{vados}^{12}$.

\section{SU UTILIZACIÓN COMO TÉCNICA INSTRUMENTAL DE POLICÍA EN LA NUEVA LEY $9 / 2017$}

La técnica contractual puede ser utilizada, igualmente, por el legislador, para asegurar la adecuación al ordenamiento jurídico - específicamente, al derecho ambiental internacional, comunitario e interno- de la actuación de los licitadores, pero, sobre todo, de los contratistas.

Como se verá más abajo (IV, 1.2 y 2) la nueva Ley 9/2017 impone al órgano de contratación el rechazo de las ofertas incursas en baja temeraria como consecuencia del incumplimiento de la normativa ambiental (art. 149.4), y le atribuye igualmente un poder de supervisión del cumplimiento de la legalidad ambiental por la empresa adjudicataria (art. 201). Esto supone una potestad nueva, que va más allá del tradicional control del cumplimiento del clausulado contractual, y que sitúa al órgano de contratación en la órbita de las competencias de los órganos de control sectorial activo de la actividad económica.

10 Esto puede tener efecto, especialmente, en los sectores en los que la Administración pública constituye un elemento esencial de la demanda del mercado, como la construcción (obras públicas), la salud (hospitales) o los transportes (ferrocarriles, servicios de transporte regular por carretera, etc.): Comisión Europea (2016), Adquisiciones ecológicas. Manual sobre la contratación ecológica, $3^{\text {a }}$ edic., Luxemburgo (pág. 5).

11 Cfr. Gimeno Feliú (2013: 47).

12 Sobre la contratación ecológica como técnica, no solo de adquisición, sino también de ordenación, véase S. Arrowsmith y P. Kunzlik (2009), Social and environmental Policies in EC Procurement Law. New Direcitves and New Directions, Cambridge: Cambridge University Press (págs. 21 y ss; 148). 


\section{PRINCIPIOS QUE RIGEN LA INTRODUCCIÓN DE CRITERIOS AMBIENTALES EN LA NUEVA LEY DE CONTRATOS}

\section{LA «OBLIGACIÓN» DE INCLUIR REQUISITOS AMBIENTALES Y SUS POSIBILIDADES DE INSERCIÓN}

La Directiva 2014/24 no establece una obligación de utilizar ambientalmente la contratación pública: solo una habilitación, una capacitación, para que sean los órganos de contratación los que decidan, caso por caso, la inclusión de cláusulas ambientales en los contratos que promuevan ${ }^{13}$. Sin embargo, la Ley 9/2017 parece imponer la inclusión de criterios ambientales en la contratación. Así, se podría intentar deducir de la nefasta redacción del art. 1.3:

En toda contratación pública se incorporarán de manera transversal y preceptiva criterios sociales y medioambientales siempre que guarde relación con el objeto del contrato, en la convicción de que su inclusión proporciona una mejor relación calidad-precio en la prestación contractual, así como una mayor y mejor eficiencia en la utilización de los fondos públicos. Igualmente se facilitará el acceso a la contratación pública de las pequeñas y medianas empresas, así como de las empresas de economía social.

Ahora bien, la peculiar redacción de la frase condicional y la alusión a la «convicción» parecen eliminar o, al menos, matizar, dicha obligatoriedad: ¡la convicción es un condicionante? ¿Del titular del órgano de contratación?; si el titular no está convencido, ¿debe incorporarlas?.. ¿ O la convicción es de la ley? Por otra parte, hay contratos que, por su naturaleza, difícilmente admitirían cláusulas ambientales, como los de algunos servicios intelectuales. Finalmente, tampoco del preámbulo puede deducirse una obligación clara e incondicionada de inclusión de cláusulas ambientales ni en los criterios de adjudicación (II) ${ }^{14}$, ni en las condiciones especiales de ejecución (en las que «la Ley impone la obligación al órgano de contratación de establecer en el pliego al menos una ${ }^{15}$ de

13 Tampoco lo hacían las directivas anteriores de contratos. Cfr. Pernas García (2012: 215).

14 Respecto de la «mejor relación calidad-precio», establece: «Para lograr este último objetivo por primera vez se establece la obligación de los órganos de contratación de velar por que el diseño de los criterios de adjudicación permita obtener obras, suministros y servicios de gran calidad, concretamente mediante la inclusión de aspectos cualitativos, medioambientales, sociales e innovadores vinculados al objeto del contrato» (Preámbulo, II).

15 En el proyecto de ley, el preámbulo aludía a la obligación de introducirlas, pero no se concretaba en el articulado, que solo planteaba la posibilidad — que no obligación- 
las condiciones especiales de ejecución de tipo medioambiental, social o relativas al empleo que se listan en el artículo 202» (V) ${ }^{16}$; esta alusión conjunta a todas las cláusulas de contratación estratégica en general elimina realmente la obligación de incluir ahí cláusulas específicamente ambientales ${ }^{17}$ ).

Por eso, la vía que propone la propia Directiva 2014/24, "contratos», es la progresiva incorporación de cláusulas ambientales obligatorias a través de la legislación sectorial ${ }^{18}$. Sin perjuicio de lo anterior, algunas normas sectoriales sí que imponen cláusulas ambientales en determinados contratos: así, la Ley 2/2011, de 4 de marzo, de Economía Sostenible ${ }^{19}$, que obliga a considerar los consumos y la contaminación de los vehículos de transporte terrestre en las adquisiciones públicas (art. 106 20), o el Reglamento (UE) 106/2008, de 15 de enero, relativo a un programa comunitario de etiquetado de la eficiencia energética

de incluir este tipo de cláusulas.

16 Como seńala el art. 202: «1. [...] En todo caso, será obligatorio el establecimiento en el pliego de cláusulas administrativas particulares de al menos una de las condiciones especiales de ejecución de entre las que enumera el apartado siguiente. 2. Estas condiciones de ejecución podrán referirse, en especial, a consideraciones económicas, relacionadas con la innovación, de tipo medioambiental o de tipo social. En particular, se podrán establecer, entre otras, consideraciones de tipo medioambiental que persigan: la reducción de las emisiones de gases de efecto invernadero, contribuyéndose así a dar cumplimiento al objetivo que establece el artículo 88 de la Ley 2/2011, de 4 de marzo, de Economía Sostenible; el mantenimiento o mejora de los valores medioambientales que puedan verse afectados por la ejecución del contrato; una gestión más sostenible del agua; el fomento del uso de las energías renovables; la promoción del reciclado de productos y el uso de envases reutilizables; o el impulso de la entrega de productos a granel y la producción ecológica».

17 Aunque durante la tramitación parlamentaria no faltaron enmiendas que sí propusieron la obligación de incluir, al menos, alguna cláusula ambiental, como la 437, del grupo socialista, que planteaba la incorporación de un tercer párrafo al art. 1: «En toda contratación pública se incorporarán de manera transversal y preceptiva criterios sociales y medioambientales [...]» (BOCCGG, Congreso de los Diputados, 16 de marzo de 2017, pág. 374).

18 «Parece oportuno [...] dejar que sea la legislación sectorial específica la que fije objetivos obligatorios en función de las políticas y las condiciones particulares imperantes en el sector de que se trate» (cdo. 95).

19 Que transpone la Directiva 2009/33, de 23 de abril, relativa a la promoción de vehiculos de transporte por carretera limpios y energéticamente eficientes. Cfr. P. Valcárcel Fernández (2011), «Impulso decisivo en la consolidación de una contratación pública responsable. Contratos verdes: de la posibilidad a la obligación», Actualidad Jurídica Ambiental, 18 de abril, págs. 1-11.

20 Véase infra, nota 49. 
para los equipos ofimáticos, que impone requisitos de eficiencia energética en determinados suministros (art. 6).

Finalmente, hay que recordar que la habilitación hecha por la nueva Ley 9/2017 al órgano de contratación para incluir cláusulas ambientales en los contratos públicos es extensible a todos ellos: tanto administrativos (art. 25) como privados (art. 26) y dichas cláusulas deben ejecutarse también (lógicamente) en los casos de subcontratación, con el matiz de que la responsabilidad por el incumplimiento, en su caso, recae sobre el contratista «que asumirá, por tanto, la total responsabilidad de la ejecución del contrato frente a la Administración» (art. 215.4)

\section{EL RESPETO DE LOS DEMÁS PRINCIPIOS COMUNITARIOS DE LA CONTRATACIÓN}

$\mathrm{Al}$ tener en cuenta en la contratación pública las finalidades estratégicas, se corre el riesgo de desdibujar la igualdad en la concurrencia de los contratos públicos y perder el criterio de la oferta económicamente más ventajosa como criterio de adjudicación.

Esta preocupación de que los criterios ambientales no supongan merma de la igualdad de trato, de la concurrencia y de la unidad de mercado ya se mostró en el primer pronunciamiento del Tribunal de Justicia al respecto, en 2002. Como señaló en el fallo de la STJCE de 17 de diciembre de 2002 en el as. 513/99, Concordia Bus Finland, nn. 1 y 2:

[...] cuando... la entidad adjudicadora decide adjudicar un contrato al licitador que ha presentado la oferta económicamente más ventajosa, puede tener en cuenta criterios ecológicos, como el nivel de las emisiones de óxidos de nitrógeno o el nivel de ruido de los autobuses, siempre que tales criterios estén relacionados con el objeto del contrato, no confieran a dicha entidad adjudicadora una libertad incondicional de elección, se mencionen expresamente en el pliego de condiciones o en el anuncio de licitación y respeten todos los principios fundamentales del Derecho comunitario, en particular, el principio de no discriminación.

Junto a estas limitaciones, recogidas por la jurisprudencia comunitaria, hay otras relacionadas con las anteriores, pero no mencionadas de forma expresa ni en la normativa ni en la jurisprudencia europea, aunque «van de suyo»: en especial, el requisito de que estas cláusulas "no desvirtúen el principio general de adjudicación a la oferta económicamente

21 Cfr. Directiva 2014/24, cdo. 105. 
más ventajosa, que rige esta fase de la contratación administrativa, la de adjudicación» ${ }^{22}$.

\section{EN ESPECIAL, LA NECESARIA RELACIÓN CON EL OBJETO}

\subsection{Justificación y alcance}

El preámbulo de la nueva ley reitera la necesaria vinculación con el objeto del contrato que ya expresaba la derogada: «Se incluyen en los contratos públicos consideraciones de tipo social, medioambiental y de innovación y desarrollo. [...] su introducción debe estar supeditada a que se relacionen con el objeto del contrato a celebrar» ${ }^{23}$. También en el texto se alude a ello (p. ej., arts. $127,145,202$, etc.).

La relación con el objeto - impuesta por el derecho comunitario- es clave para asegurar el respeto del principio de igualdad y no discriminación de todos los empresarios capaces de llevar a cabo la prestación. No se pueden incluir criterios meramente subjetivos, ni en los denominados «criterios de adjudicación» (que valoran la prestación) ni en las prescripciones técnicas y modos de ejecución del contrato, pero tampoco en la solvencia técnica del empresario para la ejecución, que tiene que referirse al proceso específico de producción o prestación, por lo que no cabe exigir «criterios o condiciones relativos a la política general de responsabilidad corporativa [...]». «En consecuencia, los poderes adjudicadores no pueden estar autorizados a exigir a los licitadores que tengan establecida una determinada política de responsabilidad social o medioambiental de la empresa» (Directiva 2014/24, cdo. 9724).

El concepto de "relación con el objeto del contrato" no significa que incida necesariamente en el precio o coste de la prestación contratada o en su calidad (en esos casos es evidente); va más lejos, porque incluye actuaciones que no afectan ni a la calidad ni al coste de la prestación (p. ej., que los trabajadores que elaboran el producto sean mujeres u hombres no influye ni en un menor precio ni en una mayor calidad ${ }^{25}$; lo mismo cabe decir de la mayor o

22 Resolución 210/2016 del Tribunal Administrativo Central de Recursos Contractuales.

23 Era exigible, según el derogado TRLCSP, en la determinación de los requisitos de solvencia (art. 62); en la redacción de prescripciones técnicas particulares (art. 117.1) y en la determinación de los criterios de selección (art. 150.1). Véase, igualmente, el cdo. 104 de la misma Directiva 2014/24.

25 Por eso es criticable la conclusión del Acuerdo 80/2016, de 30 de agosto, del Tribunal Administrativo de contratos públicos de Aragón, cuando señala en su FD $3^{\circ}$ in fine: «[...] considera el Tribunal que las previsiones cuestionadas por el recurren- 
menor capacidad de contratar trabajadores desempleados de una empresa para realizar el encargo contractual): «los poderes adjudicadores también pueden elegir criterios de adjudicación basados en consideraciones de carácter social, que pueden referirse a los usuarios o a los beneficiarios de las obras, suministros o servicios objeto del contrato, pero también a otras personas»: STJUE de 10 de mayo de 2012, as. C-368/10, Comisión c. Países Bajos, n. 85²6). De hecho, el Dictamen del Consejo de Estado sobre el Anteproyecto de Ley, en la línea de las directivas y de la jurisprudencia comunitaria, interpreta que los criterios ambientales o sociales de adjudicación no tienen por qué estar justificados en que «aporte[n] valor al objeto, uso o finalidad del contrato» ${ }^{27}$, y la Ley deja claro que la relación con el objeto no tiene por qué suponer que afecte a la sustancia material de las prestaciones (art. 145.6, en relación con los criterios de adjudicación ${ }^{28}$ ).

te - plan de conciliación social - como criterio de adjudicación, no quiebran las reglas expuestas, pues existe una vinculación con la mejor calidad en la prestación del servicio». Es palmario que el servicio en cuestión, de limpieza, no tiene más o menos calidad por el hecho de que se contraten — como era el caso- desempleados de más de 45 ańos o personas con una discapacidad mayor del $50 \%$, sin perjuicio de su mayor «eficacia social».

26 Esta afirmación está inspirada, sin duda, en las Conclusiones Generales de la abogada general cuando señala (103) que, de acuerdo con el art. 53.4 de la Directiva 2004/14: «el poder adjudicador podrá regirse por criterios destinados a satisfacer exigencias sociales que, en particular, respondan a necesidades — definidas en las especificaciones del contrato- propias de las categorías de población especialmente desfavorecidas a las que pertenezcan los beneficiarios/usuarios de las obras, suministros y servicios que son objeto del contrato». Ese «en particular» justifica la afectación de las cláusulas a la prestación, pero, precisamente por eso, implica una limitación para la inclusión de cláusulas desvinculadas de la prestación (que, lógicamente, exigirá una especial motivación y menor peso en la adjudicación).

27 Dictamen 1116/2015, de 10 de marzo de 2015, pág. 155.

28 «Se considerará que un criterio de adjudicación está vinculado al objeto del contrato cuando se refiera o integre las prestaciones que deban realizarse en virtud de dicho contrato, en cualquiera de sus aspectos y en cualquier etapa de su ciclo de vida, incluidos los factores que intervienen en los siguientes procesos: a) en el proceso específico de producción, prestación o comercialización de, en su caso, las obras, los suministros o los servicios, con especial referencia a formas de producción, prestación o comercialización medioambiental y socialmente sostenibles y justas; b) o en el proceso específico de otra etapa de su ciclo de vida, incluso cuando dichos factores no formen parte de su sustancia material». 
3.2. Las cláusulas «estratégicas» no deben desnaturalizar la «oferta económicamente más ventajosa»

Este tipo de actuaciones, que «tiene relación con» el objeto, pero carece de efectos sobre la prestación que reciben los destinatarios, es el que plantea mayores problemas, porque puede distorsionar el concepto de «oferta económicamente más ventajosa» para la Administración introduciendo elementos de interés público que no se refieren a las necesidades de la Administración contratante ni de los usuarios del servicio o destinatarios de la prestación, sino de toda la sociedad o de determinados sectores (menor ruido en la fabricación del producto, utilización de energías renovables en su producción ${ }^{29}$, mayor empleabilidad, empleo de discapacitados). Se trata de condiciones relativas al proceso de ejecución del contrato (Directiva 2014/24, cdo. 104), aunque no se refieran a la prestación que se recibe.

La Administración contratante, con el objeto de satisfacer el interés público, puede legítimamente ayudar - estimular - la promoción social entre las empresas o la actividad protectora del medio ambiente de estas. Es decir, en lo que hace referencia a las características sociales y ambientales que no benefician a los destinatarios del bien o servicio, el papel de la Administración no es el del órgano de contratación tradicional (que busca el menor coste y la máxima calidad), sino el de la Administración promotora de actuaciones de interés público mediante ayudas públicas (no olvidemos que, en estos ámbitos, la contratación pública puede ser actividad de «fomento») ${ }^{30}$. Por eso, en estos casos, el contrato

29 Esta previsión permite la introducción de determinados criterios de valoración «invisibles», no vinculados a los destinatarios de la prestación o a su precio sensu stricto. Véase P. Kunzlik (2009), "The procurement of «Green» energy», en S. Arrowsmith y P. Kunzlik (eds.), Social and environmental Policies in EC Procurement Law. New Directives and New Directions (págs. 369-407), Cambridge: Cambridge University Press (págs. 402-403).

30 Esta intuición puede encontrar también justificación normativa en las primeras directivas contratos: la misma Directiva $71 / 305$, tras establecer la alternativa precios vs. criterios económicos en la «oferta económicamente más ventajosa» (art. 29.1), señala en el parágrafo $4^{\circ}$ del mismo artículo 29: «Las disposiciones del párrafo 1 [criterios económicos] no se aplicarán cuando un Estado miembro se base en otros criterios para la adjudicación de los contratos, en el marco de una regulación fijada para que ciertos participantes gocen de una preferencia a titulo de ayuda, con la condición de que la regulación invocada sea compatible con el Tratado y en particular con los artículos 92 y siguientes». En definitiva, los criterios no económicos responden a ayudas públicas y caben a título de ayuda pública, si respetan los criterios de los preceptos del tratado relativos a las ayudas. Véase la STJCE de 20 de septiembre de 1988, en el as. 31/87, Bentjees, nn. 18 y 19. 
público debe cumplir la doble finalidad: obtener la prestación económicamente más ventajosa y, a la vez, ayudar a la empresa que cumpla mejor el interés público social o ambiental establecido en la ejecución del contrato.

Ahora bien, aun habiendo dos fines distintos, la causa del contrato sigue siendo, primariamente, la obtención de una prestación ${ }^{31}$. De hecho, la necesidad de la prestación se ha configurado siempre como conditio sine qua non para la convocatoria del contrato (también ahora: art. 28 Ley), pero nunca han sido imprescindibles los elementos vinculados a fines estratégicos, que podían faltar sin que el contrato dejara de ser válido: eran, por eso, criterios secundarios $^{32}$. El hecho de que la nueva ley «obligue» (en los genéricos términos señalados más arriba) a incluir cláusulas estratégicas no elimina del todo el carácter secundario que estos criterios tienen para la institución de los contratos públicos. Por lo tanto, la potestad de otorgamiento de ayudas es aquí accesoria de la contractual, y eso supone que no puede distorsionar la prestación económicamente más ventajosa, la naturaleza esencialmente económica de la contratación pública ${ }^{33}$.

Las consecuencias prácticas de esta integración de las políticas estratégicas dentro de la contractual es que aquellas son complementarias de esta («secundarias»); pueden matizarla, pueden servir como criterio interpretativo del clausulado ambiental, pero en ningún caso pueden tener mayor importancia que los criterios relativos a la prestación ni implicar la adjudicación del

31 De acuerdo con la doctrina civilista, caben dos concepciones de la causa: como la contraprestación de la otra parte y como fin, véase, por todos, D. Pouyaud (1991), La nullité des contrats administratifs, Paris: LGDJ (pág. 157). Destaca esta en los contratos públicos: R. Parada (2014), Derecho Administrativo II. Régimen Jurídico de la actividad, 21 a ed., Madrid: Open (pág. 187), pero no dejan de ser contratos, por lo que también se mantiene la referida a la contraprestación.

32 Véase, sobre el carácter secundario de los criterios ambientales y sociales en la contratación estratégica, el comentario a la sentencia "Concordia» de P. Charro (2003), "Case C-513/99, Concordia Bus Finland Oy Ab v. Helsinging kaupunki and HKLBussiliikenne, Judgement of the Full Court of 17 September 2002», Common Market Law Review, 40 (págs. 179-191). Frente a esta terminología, otros autores han defendido el carácter «horizontal» de estas políticas, porque el carácter «secundario» podría suponer una marginación de este tipo de políticas, o una consideración de que no son importantes respecto a las demás políticas: S. Arrowsmith y P. Kunzlik (2009: 13-14). Sin embargo, resulta evidente que, sin negar el carácter esencial de dichas políticas para el Estado (con reconocimiento constitucional, incluso), el primer e imprescindible objetivo del contrato es la obtención de un bien o servicio.

33 Charro (2003). Véase, infra, el criterio de adjudicación de costes del ciclo de vida, como criterio que monetariza los costes ambientales y, por tanto, combina la primacía de lo económico con la protección del medio ambiente (4.1). 
contrato a una oferta que manifiestamente no es la económicamente más ventajosa, porque se estaría produciendo desviación de poder: utilización de una potestad (la contractual) para un fin distinto del previsto por el ordenamiento, que es la obtención de la prestación económicamente más ventajosa posible.

Más en concreto, los requisitos o elementos ambientales o sociales que afecten al objeto pero no se manifiesten en la prestación (en las condiciones de adjudicación o en las de ejecución) no pueden restringir la concurrencia hasta el punto de predeterminar el prestador (por lo tanto, si se incluyen en la solvencia técnica o en las condiciones de ejecución, deben permitir el acceso de una cierta masa crítica de oferentes); pero pueden - y deben - ser tenidos en cuenta a la hora de valorar ofertas sensiblemente iguales: este debería ser su ámbito de aplicación propio. Por eso, su cuantificación a efectos de valoración de las ofertas no debería ser elevada: de acuerdo con el principio de proporcionalidad, en las condiciones de adjudicación, los aspectos que no se traduzcan en una mayor calidad de la prestación deberán tener siempre un valor tal que no impida la identificación de la oferta económicamente más ventajosa ${ }^{34}$.

\subsection{A diferencia de las cláusulas «sociales», las ambientales pueden tener un valor elevado en la adjudicación}

Dicho lo anterior, cabría admitir un valor elevado de los criterios ambientales desvinculados de la calidad de la prestación cuando estos puedan

34 En esta línea de ponderación del peso relativo de los diversos criterios, el más arriba citado Acuerdo 210/2016, del Tribunal Administrativo Central de Recursos contractuales, señala, respecto de los criterios de adjudicación «sociales» desvinculados de la prestación, como es la empleabilidad de parados y personas con discapacidad: «observando que guardan relación con el objeto del contrato y la debida proporcionalidad en su puntuación (de 0 a 5 puntos), hemos de deducir que [estas cláusulas] no resultan contrarias a Derecho porque no introducen elementos distorsionadores de la igualdad y concurrencia ni desvirtúan el principio general de adjudicación a la oferta económicamente más ventajosa, que rigen esta fase de la contratación administrativa, la de adjudicación». Véase, igualmente, el Acuerdo 45/2016 del Tribunal Administrativo de Contratos Públicos de Navarra, en el que se declaraba la nulidad de un criterio de adjudicación consistente en la valoración de la contratación de mujeres en los puestos de trabajo destinados al contrato, por considerarse que «no se justifica en el expediente que la contratación de mujeres para la prestación del servicio suponga una mejora en la prestación del servicio, ni su incidencia en el objeto del contrato, cuando es un criterio que supone 25 puntos sobre un total de 100» (cfr. J. Miranzo Díaz (2017a), «Hacia una Administración Pública sostenible: novedades en la legislación europea de contratación pública», Actualidad Jurídica Ambiental, 64, 9 de enero de 2017, págs. 1-40 (pág. 27). 
incluirse como criterios también económicos, para seleccionar la «oferta económicamente más ventajosa» prevista en el art. 1.1 (en concreto, los costes relativos al ciclo de vida: véase infra, 4.1.1), como se deduce de la jurisprudencia europea, que no tiene rubor en admitir que algunos criterios ambientales puedan tener un peso de casi un $50 \%$ en la ponderación de los criterios de adjudicación ${ }^{35}$. En efecto, los criterios relativos a la producción del bien o servicio, «aunque no forme parte de su sustancia material» (art. 145.6.b), son incluibles en los costes (económicos y ambientales) del ciclo de vida, como se deduce del art. 148.1: "se entenderán comprendidos dentro del "ciclo de vida" de un producto, obra o servicio todas las fases consecutivas o interrelacionadas que se sucedan durante su existencia y, en todo caso: la investigación y el desarrollo que deba llevarse a cabo, la fabricación o producción [...]». Por este motivo, el elevado coeficiente de ponderación de este (u otros) factores puede ser - como es el caso citado - adecuado al criterio de la «oferta económicamente más ventajosa».

En esto se diferencian los criterios sociales y ambientales: aquellos no pueden considerarse como económicos y, por tanto, su cuantificación debe ser relativamente reducida para no desvirtuar la «oferta económicamente más ventajosa», mientras que estos, prácticamente en todos los casos, pueden integrarse en los criterios económicos a través de los costes del ciclo de vida ${ }^{36}$, por lo que pueden admitir una mayor valoración cuantitativa, que no desvirtúa, sino que aplica e integra efectivamente el principio de la oferta económicamente más ventajosa (véase infra, IV, 1.1.).

35 El TJCE admite que puede haber criterios, no plasmados en la calidad de la prestación recibida, cuyo peso en la adjudicación sea relativamente elevado, por referirse al modo de producción. Véase, p. ej., la STJCE de 4 de diciembre de 2003, C-448/01, as. EVN $A G$, que establece en el fallo: «La normativa comunitaria en materia de contratación pública no se opone a que una entidad adjudicadora establezca, para la determinación de la oferta económicamente más ventajosa a efectos de la adjudicación de un contrato de suministro de electricidad, un criterio consistente en exigir el suministro de electricidad generada a partir de fuentes de energía renovables, al que se atribuye un coeficiente de ponderación del $45 \%$ [...]» (véanse, igualmente, nn. 36 y 39). Cfr. M. M. Razquin Lizarraga (2017), «Mecanismos para la inclusión de cláusulas ambientales en los contratos públicos», en M. M. Razquin Lizarraga (coord.), Nueva contratación pública: mercado y medio ambiente (págs. 147-178), Cizur Menor: Thomson Reuters Aranzadi.

36 J. Miranzo Díaz (2017a: 26). 


\section{4. ¿Caben cláusulas ambientales «subjetivas»? $?^{37}$}

De acuerdo con la EM (V) de la Ley, las consideraciones ambientales podrán incluirse «tanto al diseñarse los criterios de adjudicación, como criterios cualitativos para evaluar la mejor relación calidad-precio, o como condiciones especiales de ejecución». Pero a estas dos ubicaciones hay que añadir (véase infra) la posibilidad de que el órgano de contratación exija criterios (subjetivos) de solvencia técnica en materia ambiental.

La solvencia técnica para poder celebrar contratos con la Administración es un requisito subjetivo y, como tal, no puede ser utilizado como criterio de adjudicación (valoración de ofertas); pero condiciona la participación en un procedimiento contractual o incluso puede exigirse en la fase de selección de los invitados a presentar proposiciones en un procedimiento restringido (cfr., art. 160 $)^{38}$. Se puede acreditar mediante certificación de gestión medioambiental $^{39}$, como establece el art. 94.1 de la Ley:

En los contratos sujetos a una regulación armonizada, cuando los órganos de contratación exijan como medio para acreditar la solvencia técnica o profesional

37 Sin perjuicio del clausulado contractual, la ley con carácter general establece los requisitos subjetivos de capacidad y solvencia exigibles a los contratistas. No son cláusulas del contrato, sino condiciones previas normativas y generales, aplicables a todos los contratos; se trata de requisitos legales subjetivos que pueden calificarse como «requisitos de capacidad (positivos)» y "causas de incapacidad», dentro de las cuales se incluyen las tradicionales prohibiciones de contratar, dirigidas a asegurar la fiabilidad del contratista. Entre ellas, se mantienen en la nueva ley la comisión de determinados delitos medioambientales (relativos a la ordenación del territorio y el urbanismo, la protección del patrimonio histórico y el medio ambiente) y la comisión de algunas infracciones muy graves en materia medioambiental (art. 71 a), b) y c)). La adjudicación a un contratista sancionado por estos motivos genera la nulidad de pleno derecho del contrato (art. 39.2 a) Ley).

38 Así, la solvencia, no susceptible, en principio, de ser utilizada como criterio de valoración de ofertas, permite restringir el acceso a la fase de ejecución a aquellos empresarios que ofrecen mayores garantías para integrar la variable ambiental en la ejecución del contrato, porque en este tipo de procedimientos deben valorarse tanto los aspectos objetivos (en la valoración de las ofertas) como los subjetivos (en la selección de los «invitables»), cfr. Pernas García (2012: 193).

39 Como señala la Directiva 2014/24 en su cdo. 88: «Los sistemas de gestión medioambiental, estén o no registrados con arreglo a instrumentos de la Unión Europea, como el Reglamento (CE) 1221/2009 del Parlamento Europeo y del Consejo, pueden demostrar que el operador económico tiene la capacidad técnica necesaria para ejecutar el contrato». 
la presentación de certificados expedidos por organismos independientes que acrediten que el licitador cumple determinadas normas de gestión medioambiental, harán referencia al sistema comunitario de gestión y auditoría medioambientales (EMAS) de la Unión Europea, o a otros sistemas de gestión medioambiental reconocidos [...].

Ahora bien, para ello es preciso que la solvencia técnica ambiental que se pretende acreditar se refiera al proceso específico de producción o prestación de las obras, suministros o servicios susceptibles de ser adquiridos, esto es, que tenga relación directa con el objeto del contrato ${ }^{40}$, tal y como señala la jurisprudencia del TJUE y la propia Directiva transpuesta (2014/24).

\section{PROMOCIÓN DEL USO DE ETIQUETAS Y CERTIFICADOS DE ECOAUDITORÍAS Y SUS LÍMITES COMO PRUEBA DEL CUMPLIMIENTO DE REQUISITOS AMBIENTALES}

\section{El art. 127.2 de la Ley 9/2017 establece:}

Cuando los órganos de contratación tengan la intención de adquirir obras, suministros o servicios con características específicas de tipo medioambiental, social u otro, podrán exigir, en las prescripciones técnicas, en los criterios de adjudicación o en las condiciones de ejecución del contrato, una etiqueta específica como medio de prueba de que las obras, los servicios o los suministros cumplen las características exigidas [...], siempre que se cumplan todas las condiciones siguientes $[\ldots]$.

La etiqueta ambiental —es bien sabido- no constituye un requisito necesario para la comercialización lícita de un producto; antes bien, es un sello voluntario de garantía de calidad que solo algunos productores buscan y obtienen ${ }^{41}$, aunque para evitar que la exigencia de la etiqueta ambiental pueda predeterminar al adjudicatario, la ley establece cautelas al respecto (que la etiqueta mencionada tenga relación con el objeto del contrato, que no resulte discriminatoria, que haya sido expedida por organismos fuera de la influencia del órgano de contratación, que haya sido emitida en un procedimiento abierto y transparente y que sea accesible a las partes interesadas: art. 127.2).

40 Así lo establece también el Manual sobre la contratación pública ecológica, cit., pág. 39. Se trata, en definitiva, de «la experiencia anterior de las empresas a la hora de llevar a cabo contratos que tuvieran requisitos medioambientales similares» (pág. 40).

41 Í. Sanz Rubiales (2000), "Sobre la naturaleza jurídica de la etiqueta ecológica», en El Derecho Administrativo en el umbral del siglo XXI (Homenaje al Profesor Dr. D. Ramón Martín Mateo), tomo III (págs. 3693-3710), Valencia: Tirant lo Blanch. 
Ahora bien, como la etiqueta cumple una función de medio de prueba de determinadas características ambientales, no puede el órgano de contratación remitirse exclusivamente a una etiqueta en concreto (porque cabe probar la existencia de las características certificadas mediante otras etiquetas —art. 127.3-) ni a las características de una etiqueta si no las ha expuesto en los pliegos y son suficientemente conocidas por los interesados (art. 127.5) ${ }^{42}$. De esta forma desaparece el carácter obligatorio que tenían las etiquetas en el proyecto de ley, con la única excepción de la imposibilidad demostrada, y se pone en línea con las directivas de contratos y la jurisprudencia del TJUE.

La ley alude de forma expresa a las etiquetas ambientales, en general (art. 127), pero también, y específicamente, a los certificados de gestión ambiental —especialmente, a los comunitarios (EMAS) — a efectos de demostrar la solvencia técnica del empresario (art. 9443). De esta forma, considera a los poderes adjudicadores consumidores ambientalmente responsables; configura las etiquetas ambientales y los sistemas de gestión voluntarios y, específicamente, el EMAS, como técnicas de referencia en la materia y, finalmente, muestra una evolución en la exigibilidad de este tipo de instrumentos, formalmente voluntarios, que si bien nacieron como simples técnicas de fomento basadas en el mercado (dirigidas a promover procesos o productos ecológicos, a efecto de obtener una imagen "verde» en el mercado entre privados), ahora amplían sus utilidades al ámbito de la contratación pública y se acercan más

42 Según el TJUE, no deberían los órganos de contratación exigir etiquetas, sino una serie de características técnicas que pueden ser demostradas por etiquetas u otros medios, indicando además los criterios en que se basan esas etiquetas. Así se deduce de la STJUE de 10 de mayo de 2012, as. C-368/10, Comisión c. Países Bajos, n. 97. Cfr. Betancor Rodríguez (2014: 1459-1460).

43 «1. En los contratos sujetos a una regulación armonizada, cuando los órganos de contratación exijan como medio para acreditar la solvencia técnica o profesional la presentación de certificados expedidos por organismos independientes que acrediten que el licitador cumple determinadas normas de gestión medioambiental, harán referencia al sistema comunitario de gestión y auditoría medioambientales (EMAS) de la Unión Europea, o a otros sistemas de gestión medioambiental reconocidos de conformidad con el artículo 45 del Reglamento (CE) n. ${ }^{\circ}$ 1221/2009, de 25 de noviembre de 2009, o a otras normas de gestión medioambiental basadas en las normas europeas o internacionales pertinentes de organismos acreditados. 2. Los órganos de contratación reconocerán los certificados equivalentes expedidos por organismos establecidos en cualquier Estado miembro de la Unión Europea y también aceptarán otras pruebas de medidas equivalentes de gestión medioambiental que presente el licitador, $y$, en particular, una descripción de las medidas de gestión medioambiental ejecutadas, siempre que el licitador demuestre que dichas medidas son equivalentes a las exigidas con arreglo al sistema o norma de gestión medioambiental aplicable». 
a una carga para participar en determinados contratos públicos. En efecto, especialmente en algunos sectores, las empresas necesitan, en la práctica, de la adjudicación de contratos públicos; para ellas, las etiquetas ambientales o el certificado de gestión medioambiental (ambos, voluntarios) se convierten, en la práctica y por razones de eficiencia, en obligatorios, so pena de tener que demostrar, caso por caso en cada contrato, el cumplimiento de todas y cada una de las medidas que las citadas etiquetas o certificaciones acreditan.

\section{LA NECESARIA COHERENCIA CON LAS DEMÁS FINALIDADES ESTRATÉGICAS DE LA CONTRATACIÓN PÚBLICA}

Estamos, sin duda alguna, ante un campo de experimentación legislativa de la UE. Se trata de la utilización de la política contractual comunitaria (nacida para luchar contra las distorsiones a la concurrencia derivadas de la soberanía de los Estados miembros) mediante la introducción, primero vía jurisprudencial, y después por previsión de las directivas, de cláusulas ambientales o sociales que afectan a la configuración económica de la contratación pública.

Ahora bien, las previsiones de la Directiva contratos de 2014 y de la Ley de transposición plantean serios problemas en lo que se refiere a la exigencia de criterios de excelencia en la protección ambiental y, en concreto, al etiquetado verde y a los sistemas de gestión ambiental (especialmente, EMAS). En efecto, la promoción del sistema EMAS de gestión ambiental como criterio de solvencia técnica (al igual que el etiquetado ambiental o social, en su caso) no contribuye a mejorar el acceso de las pymes a la contratación pública. Estas empresas, por su reducido tamaño, pueden no estar en condiciones de acceder con facilidad a los procesos de control de ecoetiquetas y ecoauditorías ${ }^{44}$, técnicas que son asequibles, sin embargo, a las grandes empresas ${ }^{45}$. De ahí que la

44 Así lo hace notar la propia Directiva 2014/24, en su cdo. 84: «Muchos operadores económicos, y en concreto las PyMEs, consideran que un obstáculo importante para su participación en la contratación pública son las cargas administrativas que conlleva la obligación de presentar un número sustancial de certificados u otros documentos relacionados con los criterios de exclusión y de selección. Limitar estos requisitos [...] podría aportar una simplificación considerable que beneficiaría tanto a los poderes adjudicadores como a los operadores económicos». Sin embargo, como se verá infra, la exigencia de etiquetas sociales o ambientales — definidas por la propia Directiva (art. 2.1.23) como "cualquier documento, certificado o acreditación que confirme que las obras, productos, servicios, procesos o procedimientos de que se trate cumplen determinados requisitos»— puede perjudicar a las pymes en su acceso a la contratación pública. Así se pone de manifiesto en la enmienda 549 del Congreso de los Diputados, de modificación del art. 94 del Proyecto, que proponía la posibilidad de acreditación del 
aplicación de las cláusulas ambientales (o sociales, en su caso) no debería tener efectos restrictivos del acceso de las pymes al proceso de contratación.

\section{LAS NOVEDADES DE LA LEY 9/2017 EN LAS DISTINTAS MODALIDADES DE CLÁUSULAS AMBIENTALES}

Las consideraciones ambientales pueden incluirse como criterios de adjudicación, que constituyen «la base para hacer una evaluación comparativa de la calidad de las ofertas" y como condiciones de ejecución , esto es, como «requisitos objetivos fijos que no inciden en la evaluación de las ofertas» (Directiva 2014/24, cdo. 104). En ambos tipos de cláusulas, la nueva Ley 9/2017 aporta novedades importantes.

\section{LA ACERTADA «AMBIENTALIZACIÓN»DE LOS CRITERIOS ECONÓMICOS DE ADJUDICACIÓN DE LOS CONTRATOS}

La posibilidad de inclusión de criterios ambientales a título de criterios de adjudicación de contratos ya estaba reconocida en la Directiva "contratos» de $2004^{46}$ y en el TRLCSP (art. 150.1), entre muchos otros, además del precio. Como es sabido, el criterio genérico de adjudicación utilizado por las directivas y el TRLCSP es el de la "oferta económicamente más ventajosa», que podía basarse exclusivamente en un criterio, en cuyo caso sería el precio más bajo (art. 150.1 TRLCSP) o en varios (incluidas las características medioambientales) (art. 150.2, 3 y 4 TRLCSP).

La nueva ley establece, igual que la anterior, un listado de contratos que deben adjudicarse teniendo en cuenta varios criterios y no solo el de los costes (art. 145.3), entre los que se incluyen aquellos que pueden tener un impacto significativo en el medio ambiente (h). Pero, además, distingue entre criterios económicos y cualitativos; dentro de los segundos mantiene las características ambientales, sociales o innovadoras como criterios de adjudicación (art. 145.2); pero, entre los primeros, recoge dos posibilidades: el precio o la rentabilidad, ejemplificada en el coste del ciclo de vida (art. 145.2 in fine). El coste

cumplimiento de las normas de gestión ambiental a través de «medidas equivalentes» a los certificados EMAS o equivalentes emitidos por los Estados miembros, a título de «mejora técnica para promover la participación de las pequeñas y medianas empresas (pymes) en los procesos de contratación pública» (BOCCGG, Congreso de los Diputados, 16 de marzo de 2017, pág. 446).

46 Directiva 2004/18, cdo. 1; arts. 23.3, 23.6, 26, 50, etc. 
del ciclo de vida recoge el precio de adquisición y los costes posteriores, de la vida y «muerte» del producto, que debe soportar el adquirente.

1.1. El nuevo criterio de los costes del «ciclo de vida» como demostración de que los costes ambientales son también económicos

A. Es un criterio económico que incluye costes «ambientales»

La nueva ley apunta a un cambio de planteamiento fundamental, porque incluye el denominado "ciclo de vida» como un criterio económico de adjudicación de los contratos, equiparable al del precio ${ }^{47}$. Este criterio, novedoso en el ámbito de los contratos públicos y de origen contable, se forja sobre la constatación de que los costes en los que incurre un comprador después de haber adquirido un producto suponen, con frecuencia, una parte muy importante de los costes vinculados al ciclo de la vida del citado bien, hasta el punto de ser determinantes para decidir la compra del producto ${ }^{48}$. Ha sido introducido para la contratación pública en España por el art. 106 de la Ley de Economía Sostenible para la adquisición de vehículos automóviles mediante contratos públicos $^{49}$; no obstante, con anterioridad ya había sido utilizado en la contratación pública por otros países ${ }^{50}$.

47 Se puede calificar como la principal novedad de la Directiva 2014/24 en materia ambiental: J. Miranzo Díaz (2017b), «Los criterios de adjudicación ambientales en las Directivas de 2014», en M. M. Razquin Lizarraga (coord.), Nueva contratación pública: mercado y medio ambiente, págs. 383-404 (pág. 395), Cizur Menor: Thomson Reuters Aranzadi.

E. Castelló Catiani (1994), «Los costes del ciclo de vida del producto: marco conceptual en la nueva contabilidad de gestión", Revista española de financiación y contabilidad, 81 (págs. 929 y ss., 946).

49 "Artículo 106. Adquisición, por los poderes adjudicadores, de vehículos de transporte por carretera limpios y energéticamente eficientes. 1. Las entidades a que se refiere el artículo anterior [poderes adjudicadores], en sus adquisiciones de vehículos de trasporte por carretera que realicen a partir del 4 de diciembre de 2010, tendrán en cuenta los impactos energético y medioambiental de la utilización durante la vida útil del vehículo, con arreglo al apartado 2, y aplicarán una de las opciones previstas en el apartado 3 de este artículo. 2. Los impactos energético y medioambiental de la utilización que deberán tenerse en cuenta incluirán al menos lo siguiente: a) el consumo de energía; b) las emisiones de $\mathrm{CO}_{2}$, y c) las emisiones de $\mathrm{NO}_{x}, \mathrm{NMHC}$ y partículas». Asimismo, la DA $6^{\mathrm{a}}$ establece la metodología para el cálculo de los costes de utilización durante la vida útil de los vehículos contemplados en el artículo 106 de esta ley.

50 Véase O. Perera, B. Morton y T. Perfrement (2009), Life Cycle Costing in Sustainable Public Procurement: A Question of Value, Winnipeg, Canadá: International Institute for Sustainable Development (IISD). 
El criterio del «ciclo de vida» es un criterio económico, puesto que se concreta en costes, tanto de adquisición (el precio de compraventa del producto) como vinculados a la vida de dicho producto (art. 148.1). Pero, a la vez, es un criterio netamente ambiental. Como señala el art. 148.2, incluye:

a) Los costes sufragados por el órgano de contratación o por otros usuarios, tales como:

$1^{\circ}$. Los costes relativos a la adquisición.

$2^{\circ}$. Los costes de utilización, como el consumo de energía y otros recursos.

$3^{\circ}$. Los costes de mantenimiento.

$4^{\circ}$. Los costes de final de vida, como los costes de recogida y reciclado.

b) Los costes imputados a externalidades medioambientales vinculadas al producto, servicio u obra durante su ciclo de vida, a condición de que su valor monetario pueda determinarse y verificarse; estos costes podrán incluir el coste de las emisiones de gases de efecto invernadero y de otras emisiones contaminantes, así como otros costes de mitigación del cambio climático.

Respecto de los primeros, los costes sufragados por el adquirente o, en su caso, por los usuarios, lógicamente, son ambientales los vinculados al consumo de energía, el consumo de otros recursos naturales (la denominada «huella del agua», minerales transformados, vegetales, etc. ${ }^{51}$ ) y los costes de recogida y reciclado, característicos de la gestión de residuos ${ }^{52}$. Todo ello encaja dentro del concepto de sostenibilidad de las actividades económicas. Se trata de costes económicos fácilmente cuantificables que soporta el adquirente desde la adquisición.

También son ambientales, como su nombre indica, los costes vinculados a externalidades ambientales. Estos no son fácilmente cuantificables y se producen no solo durante la utilización del producto, sino también durante su

51 El consumo de energía, ya sea directamente derivada de combustibles fósiles, ya sea eléctrica (mientras una buena parte del pool eléctrico español sea de origen fósil o nuclear), implica una importante afectación al medio ambiente (cambio climático, emisiones de $\mathrm{CO}_{2}$ y de otras sustancias contaminantes, vertidos de las centrales térmicas, generación de residuos — radiactivos o no-, etc.). Respecto de los otros recursos consumidos durante la vida del producto, cabe destacar el consumo de agua (con la previa depuración y la gestión de las residuales), de productos químicos (limpieza, etc.).

52 Entre los costes de final de vida destaca la gestión de residuos (de acuerdo con las previsiones de la Ley 22/2011, de 28 de julio, de Residuos y Suelos contaminados). En el mismo sentido, Pernas García (2012: 183-184). 
producción. Las externalidades (que pueden ser positivas o negativas) son los efectos reales y no buscados que la actividad de un agente económico produce en el nivel de bienestar de otro, y en el caso de las ambientales negativas ${ }^{53}$, se identifican con la producción de la contaminación, con los daños o costes producidos por la actividad de las empresas que el mercado por sí solo no puede valorar y muy difícilmente castigar. El problema aquí es la determinación del valor monetario: salvo la «huella de carbono» de determinados productos europeos, cuyo valor es calculable con una relativa facilidad gracias al mercado de emisiones regulado por la Directiva 2003/87 y la Ley 1/2005, del mercado de derechos de emisión de gases de efecto invernadero, resulta difícil determinar el valor monetario de estas externalidades, si no existe un mercado ad hoc, un impuesto específico al respecto (canon de vertidos, impuestos por emisiones contaminantes, etc.) o criterios de medición normalizados.

En definitiva, el legislador europeo ha descubierto, gracias a este criterio económico de medición de costes, que el medio ambiente está implicado de forma inescindible en el objeto de prácticamente todos los contratos públicos de obras, en muchos de suministros y en algunos de servicios ${ }^{54}$ : todos aquellos contratos en los que se pueda utilizar el criterio del coste del ciclo de vida tienen incidencia ambiental y deberá tenerse en cuenta la protección del ambiente en su adjudicación y en su ejecución.

Queda claro, por lo tanto, que el criterio económico, cuando se concreta en el coste del ciclo de vida, es realmente económico-ambiental ${ }^{55}$.

\section{B. Puede utilizarse como criterio único de adjudicación}

Con este criterio, lo ambiental pasa a ser un criterio de valoración habitual porque, como señala el art. 146.1, «Cuando sólo se utilice un criterio de adjudicación, este deberá estar relacionado con los costes, pudiendo ser el precio o un

53 M. Buñuel González (1999), El uso de instrumentos económicos en la política del medio ambiente, Madrid: Consejo Económico y Social de España (pág. 234).

54 Véase la Comunicación de la Comisión Contratación pública para un medio ambiente mejor, pág. 8; Comisión Europea (2016: 60 ss.).

55 Este criterio de medición de costes se puede aplicar también en ámbitos distintos de la contratación pública. Véase, p. ej., el RD 56/2016, de 12 de febrero, por el que se transpone la Directiva 2012/27/UE del Parlamento Europeo y del Consejo, de 25 de octubre de 2012, relativa a la eficiencia energética, en lo referente a auditorias energéticas, acreditación de proveedores de servicios y auditores energéticos y promoción de la eficiencia del suministro de energía, que propone que las auditorías energéticas a las que deben someterse las grandes empresas se fundamenten, siempre que sea posible, en los costes del ciclo de vida (art. 3.3.c)), de acuerdo con la directiva que transpone. 
criterio basado en la rentabilidad, como el coste del ciclo de vida calculado de acuerdo con lo indicado en el artículo 148». Es decir, en aquellos contratos en los que no sea preciso valorar otras características cualitativas, el criterio del coste del ciclo de vida puede ser el único y, por tanto, determinante de la adjudicación.

Por otra parte, el hecho de que el coste del ciclo de vida pueda configurarse como criterio único de adjudicación supone que la tradicional preferencia por los criterios económicos de adjudicación ${ }^{56}$, criticada por algunos autores $^{57}$, es perfectamente compatible con la valoración de los criterios ambientales porque este sistema monetariza los costes ambientales.

\section{Dificultad para su concreción}

A diferencia del precio de adquisición - criterio totalmente reglado y cuantificado que no da lugar a interpretaciones-, el criterio del coste del ciclo de vida no permite el automatismo en la selección de contratistas a efectos de la adjudicación, tal y como se deduce del art. 148.2 in $f i n e^{58}$ y $3^{59}$. Por una

56 Así se deduce de la exposición de motivos de la Directiva 2014/24, cdo. 92: «Para determinar cuál es la oferta económicamente más ventajosa, la decisión relativa a la adjudicación del contrato no debe basarse únicamente en criterios no relacionados con los costes. Por ello, los criterios cualitativos deben ir acompañados de un criterio relacionado con los costes, el cual, a elección del poder adjudicador, podría ser el precio o un planteamiento basado en la rentabilidad, como el coste del ciclo de vida».

57 Afirma Aymerich que, en las directivas europeas, los criterios sociales y ambientales siguen subordinados a las consideraciones estrictamente económicas y competitivas, a diferencia del sistema norteamericano, en el que los objetivos políticos — cualesquiera que sean- no se encuentran subordinados a los criterios de carácter económico o competitivo en la contratación pública: C. Aymerich Cano (2017), «La contratación pública en el TTIP», Revista Vasca de Administración Pública, 107-I, págs. 19-41 (pág. 35). En defensa de un equilibrio entre los aspectos económicos y de sostenibilidad, véase J. González García (2010), «Sustainability and Public Procurement in the Spanish Legal System», en R. Caranta y M. Trybus (eds.), The Law of Green and Social Procurement in Europe (págs. 235-257), Copenhagen: DJØF Publishing, que afirma que la prestación objeto del contrato es tan importante como el procedimiento por el que se tramita dicho contrato y que el objetivo principal del contrato no es solo la prestación, sino la sostenibilidad (ambiental o social). Por eso habla del necesario equilibrio entre los criterios de sostenibilidad y la libre competencia.

58 «En los casos en que una norma de la Unión Europea haga obligatorio un método común para calcular los costes del ciclo de vida, se aplicará el mismo a la evaluación de los citados costes».

59 «Cuando los órganos de contratación evalúen los costes mediante un planteamiento basado en el cálculo del coste del ciclo de vida, indicarán en los pliegos los datos que 
parte, existen numerosos métodos de valoración de las diversas circunstancias que se tienen en cuenta en este criterio; por otro - y esto es inevitable-, el coste de vida tiene incertidumbre, porque de ordinario se desconoce el precio de los recursos ambientales y nadie sabe lo que va a durar un producto realmente: solo se puede hacer una estimación. La indeterminación puede llegar a afectar al principio de igualdad y no discriminación. De ahí la necesidad de disponer de métodos armonizados y simplificados de evaluación económica $^{60}$. El derecho comunitario va avanzando en ello: «Parece oportuno [... fomentar el desarrollo y la utilización de enfoques europeos para el cálculo del coste del ciclo de vida como refuerzo para el uso de la contratación pública en apoyo del crecimiento sostenible» (cdo. 95). Y la nueva ley establece los requisitos del método de cálculo de dichos costes (art. 148.3 ${ }^{61}$ ), de acuerdo con la Directiva (art. 68.2).

1.2. La obligación de rechazar bajas temerarias por incumplimiento de la legalidad ambiental

El órgano ambiental debe controlar el cumplimiento de la legalidad ambiental, tanto en la selección de contratistas como en la ejecución (véase infra $)^{62}$. Así lo reconoce la ley, que amplía las potestades del órgano de contratación respecto de la normativa anterior. Cuando el criterio único

deben facilitar los licitadores, así como el método que aquéllos utilizarán para determinar los costes de ciclo de vida sobre la base de dichos datos».

60 Pernas García (2012: 185).

61 «El método utilizado para la evaluación de los costes imputados a externalidades medioambientales cumplirá todas las condiciones siguientes: a) estar basado en criterios verificables objetivamente y no discriminatorios; en particular, si no se ha establecido para una aplicación repetida o continuada, no favorecerá o perjudicará indebidamente a empresas determinadas; b) ser accesible para todas las partes interesadas; c) la información necesaria debe poder ser facilitada con un esfuerzo razonable por parte de las empresas, incluidas aquellas procedentes de Estados signatarios del Acuerdo sobre Contratación Pública de la Organización Mundial de Comercio o de otros Estados signatarios de algún otro Acuerdo Internacional que vincule a España o a la Unión Europea».

62 Como señala la exposición de motivos de la Directiva (n. 40), «El control del cumplimiento de dichas disposiciones de Derecho medioambiental, social y laboral debe realizarse en las respectivas fases del procedimiento de licitación, a saber, cuando se apliquen los principios generales aplicables a la elección de participantes y la adjudicación de contratos, al aplicar los criterios de exclusión y al aplicar las disposiciones relativas a ofertas anormalmente bajas». 
de adjudicación es el precio (cfr. art. 146.1), uno de los riesgos que puede producirse es el de las bajas temerarias, que las leyes de contratos intentan neutralizar para evitar perjuicios posteriores a la Administración.

Frente a la previsión del art. 152 TRLCSP, que posibilitaba la toma en consideración de las bajas temerarias pero no obligaba a rechazarlas ${ }^{63}$, la nueva ley establece un supuesto de rechazo obligatorio de las ofertas anormalmente bajas por incumplimiento (futuro y potencial) de la normativa ambiental. En efecto, establece el art. 149.4:

En todo caso, los órganos de contratación rechazarán las ofertas si comprueban que son anormalmente bajas porque vulneran la normativa sobre subcontratación o no cumplen las obligaciones aplicables en materia medioambiental, social o laboral, nacional o internacional [...].

Es decir, cuando se comprueba que las bajas temerarias vienen causadas por el incumplimiento de la normativa ambiental, social o laboral, no se le permite al órgano de contratación ponderar su admisión o no: sencillamente, deben rechazarse dichas ofertas ${ }^{64}$. Cumple aquí el órgano de contratación con una función de control de la legalidad ambiental (y social), a título preventivo y durante la fase de selección de contratistas, pero por referencia a la ejecución del contrato.

\section{EL NUEVO CONTROL DE LA LEGALIDAD AMBIENTAL EN LA EJECUCIÓN DEL CONTRATO}

Las cláusulas ambientales relativas a la ejecución del contrato pueden ser especificaciones técnicas del objeto del contrato o condiciones especiales de ejecución. Tanto unas como otras deben quedar previstas en los pliegos (aquellas en los técnicos: art. 124 y estas en los de cláusulas administrativas: art. 122.2, 202.2 de la nueva ley) ${ }^{65}$.

El cumplimiento de las obligaciones impuestas por la legalidad ambiental a los contratistas debe ser objeto de control en todo momento del contrato, tanto durante el procedimiento de selección de contratistas (véase supra) como durante la ejecución, de acuerdo con lo que señala la Directiva de 2014

63 Además, el TRLCSP alude al incumplimiento de la normativa laboral como posible causa de la baja posiblemente desproporcionada, pero no a la ambiental (art. 152.3 TRLCSP). Cfr. Pernas García (2012: 187).

64 Cfr. Directiva 2014/24, exposición de motivos, n. 103.

65 Así lo preveía también la normativa anterior: la Directiva 2004/18 (cdo. 29) y el TRLCSP (arts. 117 y 118). 
(cdo. 37). Ya el TRLCSP preveía la introducción de criterios ambientales en la ejecución y, además, la posibilidad de ofrecer información sobre la normativa ambiental, social y laboral aplicable, a la vez que imponía al órgano de contratación que solicitara a los licitadores o a los candidatos en un procedimiento de adjudicación de contratos que manifestaran «haber tenido en cuenta en la elaboración de sus ofertas las obligaciones derivadas de las disposiciones vigentes en materia de protección del empleo, condiciones de trabajo y prevención de riesgos laborales, y protección del medio ambiente» (art. 119).

Pero la nueva ley va más lejos, cuando establece en el art. 201 una obligación activa de control de dicha normativa que se impone al órgano ambiental:

Los órganos de contratación tomarán las medidas pertinentes para garantizar que en la ejecución de los contratos los contratistas cumplen las obligaciones aplicables en materia medioambiental, social o laboral establecidas en el derecho de la Unión Europea, el derecho nacional, los convenios colectivos o por las disposiciones de derecho internacional medioambiental, social y laboral que vinculen al Estado y en particular las establecidas en el Anexo V.

\section{1. ¿Un nuevo privilegio?}

El art. 201 no impone solo la exigencia de la declaración de cumplimiento (como el TRLCSP), sino que exige que los órganos de contratación aseguren dicho cumplimiento. Esto conlleva un control activo, tanto sobre el procedimiento de licitación como sobre la ejecución del contrato e implica, por ello, el otorgamiento de potestades administrativas de policía (supervisión y control) de la actividad de los empresarios adjudicatarios del contrato. Por lo tanto, el órgano de contratación no puede eludir la responsabilidad de que se cumpla la normativa ambiental.

Además, esta atribución legal de potestades es independiente del clausulado del contrato: no estamos ante un control del cumplimiento de la prestación pactada, sino ante potestades otorgadas por ley, relativas al cumplimiento de la legalidad objetiva ${ }^{66}$. Aunque recuerda a los poderes de policía de la Administración concedente sobre la obra o servicio concedidos (cfr. arts. 249.1 y 279.2 TRLCSP ${ }^{67}$ ), este nuevo privilegio va más lejos, porque los poderes de

66 Por eso, esta competencia no se identifica con la del «responsable del contrato», que tiene como misión "asegurar la correcta realización de la prestación pactada» (art. 62.1).

67 El control sobre la ejecución del contrato, en relación en concreto a las prestaciones (especialmente con referencia a las concesiones de servicios públicos), ha venido siendo considerado como uno de los privilegios de la Administración contratante en los contratos administrativos, aunque no han faltado, en Francia, autores y decisiones 
policía en las concesiones derivan de la responsabilidad y titularidad administrativa de la obra o servicio indirectamente gestionado ${ }^{68}$ y la nueva ley los amplía y los generaliza a todos los contratos.

Se trata, de esta manera, de un privilegio administrativo en la ejecución del contrato, que coincide parcialmente con el tradicional poder de dirección $^{69}$, porque tiene un contenido supervisor-inspector y de imposición de decisiones unilaterales, aunque su finalidad no es tanto el control de la ejecución de «lo pactado» cuanto la salvaguarda de la legalidad general ambiental. Por otra parte, se trata de una potestad de ejercicio obligatorio, porque el órgano de contratación no solo está legitimado para supervisar esa actuación, sino que está obligado a hacerlo y a adoptar las medidas correspondientes para evitar la infracción a la normativa ambiental y para imponer las penalidades propias del incumplimiento de la prestación (art. 201 in fine, que se remite al art. 192$)^{70}$. Ni que decir tiene que las penalidades, que tienen naturaleza

judiciales que exigen su consagración en el clausulado contractual. Cfr. L. Richer (1999), Droit des contrats administratifs, 2a ed., Paris: LGDJ (págs. 229 ss.).

68 Cfr. E. García de Enterría y T. R. Fernández Rodríguez (2016), Curso de Derecho Administrativo, I, 17a ed., Madrid: Civitas Thomson Reuters (pág. 779). M. Sánchez Morón incluye en esta prerrogativa la facultad de inspeccionar y de ser informado del proceso de fabricación del producto en los contratos de suministro (art. 295 TRLCSP), "pudiendo ordenar o realizar por sí misma análisis, ensayos y pruebas de los materiales que se vayan a emplear»: M. Sánchez Morón (2016), Derecho Administrativo. Parte General, 12a ed., Madrid: Tecnos (pág. 642). Ahora bien, este precepto se refiere a las características de la prestación pactada («para el estricto cumplimiento de lo convenido"), no al cumplimiento de la legalidad objetiva, como es el caso de la nueva ley. Sobre el poder de dirección, aunque tradicionalmente se le ha calificado como prerrogativa de la Administración en los contratos administrativos, realmente no lo es, porque constituye una facultad propia de quien encarga una obra, servicio o suministro a otro, también en el ámbito privado. De hecho, la ley derogada (TRLCSP, art. 210) no lo incluía entre los privilegios. Sin embargo, se puede calificar como privilegio (en más y en menos) si se le considera como una potestad de ejercicio obligatorio por razón del interés público: véase, p. ej., S. Muñoz Machado (2015), Tratado de derecho administrativo y derecho público general, tomo XIII, Madrid: BOE (pág. 150).

70 Art. 201 in fine: «El incumplimiento de las obligaciones referidas en el primer párrafo [establecidas en el derecho europeo, nacional, etc.] y, en especial, los incumplimientos o los retrasos reiterados en el pago de los salarios o la aplicación de condiciones salariales inferiores a las derivadas de los convenios colectivos que sea grave y dolosa, dará lugar a la imposición de las penalidades a que se refiere el artículo 192». Y señala el art. 192: «1. Los pliegos o el documento descriptivo podrán prever penalidades para el caso de cumplimiento defectuoso de la prestación objeto del mismo o para el supuesto de incumplimiento de los compromisos o de las condiciones especiales de ejecución del contra- 
contractual porque se prevén en el clausulado del contrato y se aplican al incumplimiento de las obligaciones contractuales, no constituyen una técnica adecuada para sancionar las infracciones de la legalidad objetiva.

2.2. La incidencia del control de legalidad sobre el régimen de responsabilidad por daños a terceros

El art. 196.1 de la Ley 9/2017 recoge la cláusula general (tradicional) de la responsabilidad por daños a terceros como consecuencia de la ejecución del contrato:

1. Será obligación del contratista indemnizar todos los daños y perjuicios que se causen a terceros como consecuencia de las operaciones que requiera la ejecución del contrato.

Esta obligación tiene dos excepciones (la de los daños producidos como consecuencia de una orden de la Administración, y la de los derivados de los vicios del proyecto elaborado por esta). Sin embargo, a la luz del nuevo art. 201, parece que debería admitirse una tercera excepción: si el órgano de contratación tiene la obligación de controlar (supervisar la adecuación a la ley ambiental de la ejecución del contrato y evitar las ilegalidades, en su caso), podrá existir también culpa in vigilando de la Administración contratante cuando los daños y perjuicios a terceros deriven de actuaciones ilegales (en materia ambiental) del contratista ${ }^{71}$.

\subsection{Crítica}

Esta incoherente atribución competencial al órgano de contratación trae su causa de la errónea transposición de la Directiva 2004/14, cuyo art. 18.2 se transpone al pie de la letra salvo en la determinación del sujeto responsable para la adopción de dichas medidas. En efecto, la directiva establece en su art. 18.2:

Los Estados miembros tomarán las medidas pertinentes para garantizar que, en la ejecución de contratos públicos, los operadores económicos cumplen las

to que se hubiesen establecido conforme al apartado 2 del artículo 76 y al apartado 1 del artículo 202».

71 Así, la responsabilidad contractual del concedente puede verse comprometida respecto de terceros por razón de las faltas cometidas en el ejercicio del control (Richer, 1999: 231). 
obligaciones aplicables en materia medioambiental, social o laboral establecidas en el Derecho de la Unión, el Derecho nacional, los convenios colectivos o por las disposiciones de Derecho internacional medioambiental, social y laboral enumeradas en el anexo X.

Son, pues, los Estados y los poderes adjudicadores (y no los órganos de contratación) los que tienen que garantizar que los operadores económicos cumplen con la normativa ambiental. El cumplimiento de la prescripción de la directiva corresponde, pues, en la transposición, al Estado, y en la ejecución, a los poderes adjudicadores o a las entidades territoriales de tutela: esta es la única manera de cumplir con el control sin violentar la distribución de competencias entre las diversas administraciones públicas y dentro de cada organización pública contratante. Por otra parte, va de suyo que serán las administraciones competentes en materia de medio ambiente las que deben asegurar el ajuste a la legalidad ambiental de los empresarios privados en su actividad comercial e industrial, sea quien sea el órgano demandante de los bienes y servicios en cuestión.

Por lo tanto, según la ley, el órgano de contratación debería asumir funciones propias de los órganos de la Administración sectorial, ambiental y social (órganos con competencias ambientales, inspectores de trabajo, etc.). No se eliminan las funciones de estos, pero se otorga al órgano de contratación una función que supera las competencias asignadas por la normativa de organización y que se añade a estas. Por ello, la interpretación más correcta del precepto («Los órganos de contratación tomarán las medidas pertinentes para garantizar...») será la que obligue a estos a informar a los competentes por razón de la materia de la adjudicación del contrato en cuestión, para que sean estos últimos los que lleven a cabo el control de legalidad correspondiente e informen de los resultados al órgano de contratación, al que se le otorga la potestad de imponer penalidades por los incumplimientos comprobados (art. 201 in fine).

\section{CONCLUSIONES}

Estamos asistiendo, en materia de contratos públicos, a una transformación del Estado meramente comprador en el Estado "ordenador», como confirma el nuevo texto legislativo de contratos públicos, en virtud del cual la Administración utilizará la potestad de compra con fondos públicos como instrumento de políticas ambientales, para ordenar la actuación privada hacia el interés general mediante los estímulos a la producción «verde» y mediante el control de la legalidad ambiental de la actuación de las empresas contratistas. 
Además, en esta materia puede apreciarse con claridad la evolución de algunas técnicas administrativas desde el fomento a la policia: algunos instrumentos jurídico-públicos como el sistema EMAS o la etiqueta ecológica, que nacen como técnicas de fomento (meramente voluntarias), se van aproximando más a técnicas de policía (cuasi obligatorias), mediante el reforzamiento de la demanda por su condición de pruebas especialmente adecuadas para demostrar el cumplimiento de requisitos ambientales y, en su caso, la solvencia técnica de los licitadores.

La exigencia de que las cláusulas ambientales tengan relación con el objeto no impide la imposición legal de prohibiciones para contratar por motivos ambientales, ni la previsión administrativa de requisitos ambientales de solvencia técnica de los licitadores. Tampoco exige que se traduzcan en una mayor calidad de la prestación para los usuarios, pues basta que se valoren en el proceso de producción del bien o servicio.

La nueva contratación verde incluye posibilidades que pueden chocar con otras medidas de carácter socialy de promoción de las pymes. Por eso, el órgano de contratación deberá ponderar los objetivos de interés general para evitar que la promoción de un tipo de cláusulas anule o neutralice los otros.

El nuevo criterio de adjudicación basado en el coste del ciclo de vida es un criterio económico que cuantifica y monetariza afecciones ambientales. La posibilidad de ser aplicado como criterio único supone la potenciación y generalización de los criterios ambientales en la selección de contratistas, aunque estamos lejos todavía de que la práctica lo recoja con esa generalidad. Asimismo, cabe diferenciar los criterios sociales y los ambientales en cuanto al peso respectivo en los criterios de adjudicación: aquellos no pueden considerarse como económicos y, por tanto, su cuantificación debe ser relativamente reducida para no desvirtuar la oferta económicamente más ventajosa, mientras que estos, prácticamente en todos los casos, pueden integrarse en los criterios económicos a través de los costes del ciclo de vida, por lo que pueden admitir una mayor valoración cuantitativa, que no desvirtúa, sino que aplica efectivamente el principio de la oferta económicamente más ventajosa. 